\title{
Conclusiones sobre "La Sociedad Conflictiva" *
}

\author{
SEMINARIO 1,-EL DERECHO, ZFORMA DE LIBERACION \\ O DE REPRESION?
}

1. La pregunta.-Puesto que la pregunta formulada encierra demasiadas ambigüedades-la palabra Derecho abarca todo un complejo de conceptos--, el seminario ha preferido la siguiente formulación: "¿El sistema jurídico de una sociedad es una forma de liberación o de represión?*

Sistema jurídico $=$ conjunto de normas juridicas que sirven para organizar la sociedad: las relaciones entre grupos, entre individuos, así como entre gri* pos e individuos.

Prescindamos también, para el caso, del problema de las relaciones existentes entre las normas del sistema jurídico y la moral, la justicia, etc... Recordemos también, de paso que la organización social no es sólo el resultado del sistema juridico: la actividad económica, la animación social, también tienen sus leyes.

Sin embargo, como el Derecho positivo sirve a cierta sociedad, la actitud positivista de muchos juristas impide, a menudo, que se plantee el problema de apreciar esta sociedad: se considera entonces el Derecho como una forma vacía, lo que no contribuye a su prestigio. La perspectiva formalista $e$, incluso, "fijistan del positivismo jurídico no puede satisfacer al espíritu.

2. Una impugnación del sistema jurídico se desarrolla a dos niveles.

1. Impugnación de principio en cuanto a la organización social por cual* quier sistema jurídico. Se considera a esta organización de por sí nociva. Dicen que impide la espontaneidad de los individuos y grupos; prohíbe, incluso, que se vivan los valores con autenticidad.

2. Impugnación de los sistemas jurídicos tales como son.

Esta crítica comprende varios aspectos:

* De acuerdo con la nota nuestra anterior, recogemos aqui algunas conclusiones de varios grupos de estudio dentro del congreso de Gallarate, al que también en la misma nota aludimos. ( $N$. de la R.) 


\section{LA SOGIEDAD CONFLIGTIVA}

- retraso frecuente con respecto a la evolución de la sociedad;

- el hecho de haber sido elaborada por una minoría que pretende adelantar la conciencia social mayoritaria ( $v$. g. abolición de la pena de muerte, monogamía en Africa, de tradición polígama, etc.);

- ineptitud para hacerse cargo de las nuevas realidades;

- rigidez respecto a casos particulares;

- excesiva complejidad, que genera la perplejidad e incomprensión del
hombre de la calle.

3. Estas impugnaciones entrañan numerosas contradicciones, que reflejan las contradicciones de la sociedad moderna y subrayan la casi imposibilidad para cualquier sistema jurídico de funcionar, de responder a la complejidad de las cosas de modo que no resulte rígido; de organizar la evolución sin violentar demasiado a la mayoría ni hundirse tampoco en la apatía y el con-
servatismo social.

4. El Derecho es un circuito ininterrumpido entre la ley y el hecho,-Circuito que, por otra parte, puede funcionar en sentido regresivo si una situación social se degrada.

El legislador y, más aún, el juez dan una solución a los conflictos a partir de un análisis real de estos conflictos e intereses subyacentes. $Y$ es a menudo, después que se ha establecido la solución, cuando se trata de justificarla jurídicamente. Ahora bien, con frecuencia, el personal judicial, por su formación, se preocupa poco de llevar a cabo a fondo y adecuadamente el análisis de la realidad social. Este defecto es responsable del juridicismo que sitúa el Derecho en un plano puramente formal. En cuanto a la justificación jurídica na aposte. riori" de las decisiones tomadas, aunque pueda incurrir también en el formalismo, es, sin embargo, esencial para evitar la arbitrariedad subjetiva de un individuo o de una categoría de individuos, que hayan de emitir una decisión: la motivación jurídica de las decisiones ofrece una justificación objetivada que permite un control social y hace posible, de este modo, una participación de la sociedad en su organización jurídica.

Si esta organización es compleja, es porque la sociedad es cada vez menos sencilla y que el Derecho no puede, sin injusticia y, por tanto, sin negarse a si mismo, dar contestaciones generales y uniformes. El recurso a los expertos y a una informática jurídica se impone cada vez más. La proliferación de las leyes no resulta tanto de un prurito legislativo como de una demanda diversificada procedente de elementos cada vez más variados que componen las sociedades modernas, subrayando también el carácter dinámico de la actividad jurídica.

5. Todo sistema jurídico tiene por objeto estabilizar las relaciones para permitir el intercambio sin demasiadas frustraciones; $y$, a este nivel, no puede ser demasiado estricto, salvo en prohibir a los hombres la satisfacción de la conquista obtenida, incluso a la fuerza. Efectivamente, esta estabilización es relativa al intercambio, cuyo carácter dinámico no puede ser eliminado; el intercambio opera, a cada instante, la puesta en tela de juicio del "statu quo" anterior. La estabilización es la condición misma para que un movimiento sea orientado y sensato, no loco. Un. sistema jurídico no puede, pues, nunca ser estático; pero una estabilización siempre renovada es esencialmente necesaria para
cualquier progreso. 
6. La coacción que el Derecho representa para el poder salvaje-toda organización entraña un aspecto de coacción-es necesaria para la libertad. Y también se pone en tela de juicio el matrimonio, lugar privilegiado para descubrir experimentalmente que la coacción del otro es condición positiva para la plenitud de personas en la misma aventura. El Derecho y la autoridad sólo tienen sentido si se sobrepasa el libre albedrío, puesto que la libertad no se reduce sólo a la elección.

7. La vida del Derecho es operar en la práctica un arbitraje entre fuerzas conflictivas e incluso antagonistas, sin poder conceder a cada uno todo lo que pide.

8. El Derecho tiene por objeto la organización social. El cristianismo ha sido el que impuso la idea de que toda organización social supone favorecer el des" arrollo de las personas. $Y$ la tesis marxista de que el Derecho tiene una función pedagógica tiene una fuente pauliniana.

9. Las ideas modernas sobre la evolución y la conciencia social que se tiene de las mismas disipa la utopia de un Derecho fijado una vez para siempre, cuyas disposiciones regularían definitivamente las relaciones sociales y conducirían de nuevo a una edad de oro situada en el pasado. Y la impugnación radical de la organización juridica es otra utopia, la de una sociedad sin coacción. Tal concepto o bien rechaza cualquier opresión ("hippies") y cualquier derecho; o bien concibe una legalidad formal sin relación con la justicia (marxismo). Se sueña entonces con una sociedad no histórica, contradiciendo el ser del hombre-un ser que evoluciona en las sociedades en marcha.

\section{SEMINARIO 2.-CONFLICTOS ENTRE INSTITUCIONES POLITICAS $Y$ MOVIMIENTOS DE IMPUGNACION.}

1. Objeto de la discusión.-La impugnación propiamente política, de oposi. ción conflictiva abierta a las instituciones, y fuera de los medios institucionales de oposición (por tanto, excluyendo, salvo para comparación, la impugnanación no conflictiva, que tiende a crear una subcultura al margen de la sociedad ("hippies", p. el.).

\section{Formas de la impugnación.}

- Muy diversas.

- En los países del Este, toma la forma de una desafición, de una falta de interés, de una resistencia pasiva, con algunos casos de rebelión abierta (salvo en la URSS, a causa de las condiciones de vida universitaria).

- En Occidente, gran variedad: escasa impugnación en Suiza (quizá a causa de la existencla de cauces institucionales de impugnación de las leyes), impugnación actualmente con ritmo aminorado y limitada en Alemania; impugnación, sobre todo, en la esfera política en España; impugnación radical, muy fragmentada en pequeñisimos grupos, y bajo influencias combinadas cristianas y marxistas, en Francia e Italia.

- En todos los casos existe un nivel fundamental de impugnación, detrás de las formas y objetivos limitados de las acciones de impugnación: la 
denuncia de cierto número de absurdos, de contradicciones, hipocresías del sistema social que, a pesar de sus afirmaciones, tiende a privar al hombre de su libertad, de su responsabilidad real en la organización de su vida, avasallándolo a las coacciones de la producción, al mantenimiento del sistema que funciona sin meta, etc. citas.)

(Nota: Estas motivaciones profundas no siempre son conscientes, ni explín

3. Causas de la aparición, hoy, de esta impugnación-Además de la causa señalada en el informe de L. Beimaert, los siguientes factores:

- Aspiraciones y necesidades más ricas, tensiones más fuertes, posibilidades de elección y decisión más grandes en los jóvenes.

- La experiencia de un contraste mayor, más escandaloso, entre, las pretensiones de las ideologías dominantes, por una parte, y las posibilidades de realizaciones que confiere el progreso moderno, y la situación hecha realmente al hombre, por otra.

\section{Ensayo de valoración.}

Elementos negativos:

- A nivel del comportamiento y la psicología de los participantes, motivaciones ambiguas, una incapacidad de aceptar las frustraciones y las coacciones inevitables de la vida social, una huida de las responsabilidades
(por lo menos, en algunos), etc.

- A nivel de su ideología, irrealismo de sus programas y criticas; insistencia casi exclusiva en la crítica, y ausencia de programas positivos; exageración de sus críticas, que son a menudo globales: rechazan la totalidad del sistema, ignoran la complejidad de la vida moderna, rehusan el análisis por la utopía. - A nivel de sus métodos, carácter destructor de los medios que emplean
a menudo.

- A nivel de las posibles consecuencias de su acción: totalitarismo (de su propio movimiento); reacción de defensa conservadora por parte de la masa, de movimientos extremistas opuestos y del Gobierno (lo cual puede comprometer las reformas necesarias).

\section{Elementos positivos:}

- Actúan como reveladores de problemas; la impugnación se refiere, además, a menudo a realidades sociales, de las cuales todo el mundo está más o menos cansado, pero sin decirlo.

- Denuncian excesos y deformaciones del sistema social, que son a menudo reales, por lo menos en el estado de tendencias ffalsificación de la democracia por la oligarquía o la tecnocracia, manipulación de la información o la publicidad, avasallamiento por la producción, etc.).

- Recuerdan valores humanos fundamentales (libertad, autonomia, comunidad, creatividad, participación, igualdad, etc.), de los cuales se admite 
a menudo con demasiada facilidad, como una evidencia que forman la base del sistema social.

- Invitan u obligan así a la sociedad a cambiar, adaptar sus estructuras e instituciones al ritmo requerido por ta evolución rápida de los valores, modos de vida, aspiraciones, etc.

5. Conclusiones: Actitudes que adoptar frente a estos movimientos de im* pugnación.

- Primero, ser "buenos lectores" de la situación, reconocer y poner en evldencia los valores reales (implícitos o expícitos) contenidos en sus utopias y críticas, analizar las situaciones que denuncian para comprobar los excesos o la exactitud de sus críticas, analizar también su propio movimiento, los límites y los riesgos de su programa, su método; dedicarse a limitar las consecuencias perjudiciales de su acción (las reacciones y los excesos de su propia acción].

- Ser nosotros mismos la "conciencia critica", que la sociedad necesita, denunciando excesos e injusticias, oponiéndonos a los mismos con el valor necesario si fuera necesario.

- Ayudar en el cambio, en la adaptación de las instituciones, por la participación en la elaboración de programas positivos, reformas profundas, empleando métodos ... que puedan desbaratar los de ellos.

\section{SEMINARIO 3,-CONFLICTOS DE VALORES EN UNA SOCIEDAD ECONOMIFICADA.}

1. El cambio que vivimos en nuestras sociedades occidentales conduce a un cambio en los puntos de referencia, en los puntos de partida, en los valores fundamentales.

De ahí la ambigüedad en la presentación de estos valores tradicionales (antes aceptados pacíficamente por todos y que ahora, por el contrario, llegan a ser obsoletos) y el origen de conflictos (entre la jerarquia de valores pasada y la venidera, que hay que "inventar", que a menudo sólo puede señalarse negativamente; conflictos entre las estructuras pasadas, portadoras de valores superados y en resistencia contra cualquier mutación, y las estructuras nacientes].

2. Este cambio mayor (umbral cualitativo) que vivimos podría interpretarse como el paso de una economía de penuria (de subsistencla) a una economía de abundancia (de consumo). Se pasa de la pobreza a la posibilidad de elección. Surgen, sucesivamente, nuevas necesidades (de supervivencia o primarias, psicológicas, de prestigio, de autorrealización, de participación, de libertad real); la concepción, el papel y la posición de la autoridad y el Estado cambian (peso relativo de lo privado-publico; de un orden que se impone a una autoridad como función al servicio de un proyecto colectivo); el trabajo cambia de significado (de una dura necesidad-la faena-a una prestación funcional, incluso un serviclo comunitario, a medida que se camina hacia una sociedad de ocio).

3. Estos cambios se eprecipitan" (aceleran y universalizan) por los medios de comunicación (efecto de imitación o demostración). 


\section{LA SOCIEDAD CONFLICTIVA}

Se subraya también que a menudo la modificación de normas (de compor tamiento exterior) ocultan una evolución en la escala de valores (fundamentales e interiores].

4. En las sociedades orientadas y planificadas se vive además una crisis de valores no confesada (divorcio de hecho entre los valores oficiales que no cambian en su formulación y los auténticos valores vividos por la gente e impuestos en la práctica a la autoridad).

5. En este contexto se ha preguntado cuál es ei impacto de este cambio mayor sobre los valores religiosos, y si estos valores pueden aún desempeñar un papel en la nueva sociedad que está naciendo.

En la penuria existía la coacción: los valores materiales se imponian; ahora hay que elegir. En esta situación, alguien ve una condición privilegiada para la recuperación de los auténticos valores religiosos (la trascendencia, la kenosis en Cristo, lo gratuito en el amor fraternal, son dimensiones estructurales cons. titutivas del hombrel so pena de la autodestrucción, personal y colectiva. Hoy cada vez más y para una creciente parte de hombres, se plantea la necesidad de esta elección radical y personal. Se adquiere la experiencia masiva e intensa de la insuficiencia y del vacio creado por los valores económicos y materiales e, incluso, sociológicos y culturales ateos (se está obligado a pasar del nivel del "tener" al del "ser", incluso del "superser"). Naturalmente, este modelo de vida debe proponerse, no imponerse, y, sobre todo, para ser eficaz. debe vivirse, ante todo, realmente por los que lo proponen; debe, por fin, concretarse no sólo en una metanoia personal, sino también en una modificación de estructuras (de ahí la necesidad de competencia técnica, económica, sociológica, psicológica, pedagógica). Otros son más escépticos en cuanto a la "ocasión histórica" que se presentará a los valores religiosos, en profunda crisis en nuestras sociedades cada vez más secularizadas. Se subraya la necesidad de nuevas formulaciones de estos valores y la indeterminación (y por eso el pluralismo) en cuanto a soluciones contingentes y a casos concretos de estos mismos valores.

6. En cuanto al método (técnica, instrumentos) para seguir y promover estos cambios (esta busca e invención de nuevas estructuras y valores estimulantes), se está de acuerdo en un diálogo, una discusión, una democracia, una partici. pación cada vez más amplia y a todos los niveles (Estado, región, barrio, fábrica, parroquia, obra apostólica).

Pero, en conjunto, se subraya que las experiencias prácticas son hasta ahora más bien decepcionantes: la autogestión es a menudo sólo un nombre; la democracia asambleística, una demagogia de líderes de masas; se tropieza con una pasividad y una negación de hecho de la participación y toma de responsabilidad.

De ahí la necesidad de crear las condiciones para esta "democracia amplia da " con una formación tendente a desarrollar las capacidades de iniciativa, elec" ción, inventiva, creatividad personal para las "formas nuevas".

\section{SEMINARIO 4,-LOS CONFLICTOS DE INTERES ENTRE PAISES RICOS $Y$ PAISES POBRES,}

1.--Campos en los que se manifiestan los conflictos:

1) Ideológicos. 
2) Culturales.

3) Económicos.

4) Políticos.

5) Tecnológicos.

$11,-$ Modos que pueden acusar estos conflictos:

1) Conflictos a largo plazo y a corto plazo.

2) Diferencias entre las situaciones juridicas y las situaciones reales.

3) Desigualdades económicas en el interior de los distintos países.

4) Conflictos entre los valores mismos en el interior de los distintos países (ise pone primero el acento en la libertad, independencia, riqueza o justicia?).

5) Conflictos entre los países pobres y las clases pobres de los países ricos (campesinos, industrias de escaso nivel tecnológico).

III,--Formas de ayuda prestada por los países desarrollados.

Esta ayuda es actualmente demasiado escasa; hay que tener en cuenta que un incremento de esta ayuda sólo tiene una influencia muy pequeña en el incremento de la renta nacional de los paises desarrollados. Sin embargo, hay que actuar para eliminar los inconvenientes que este incremento de la ayuda puede tener sobre clertas clases de los países desarrollados.

IV.- ¿Hay que desarrolar estos conflictos o intentar atenuarlos? razones.

1) Estos conflictos existen; mucha gente no quiere verlos, ni ver sus

2) Es preciso que las opiniones públicas de los paises desarrollados com. prendan que estos conflictos son más importantes que los conflictos en el interior de su propio país.

3) Ciertos conflictos sólo pueden ser resueltos por la violencia; pero ésta sólo puede justificarse si, habida cuenta de los males inherentes al uso de la violencia, se tiene la certeza de obtener resultados adecuados.

V.-¿Qué debe hacer la Iglesia? ¿Qué debemos hacer en la Iglesia?

1) Debe primero ayudar a tener conciencia de las situaciones de injusticia; tiene el deber de no ocultar nada de estas injusticias.

2) Debe invitar a los cristianos a la acción.

3) Debe contribuir a que los conflictos sean menos salvajes. 